\title{
The Pragmatic Effect of the First Person Plural Pronouns in Single-authored Scientific Articles
}

\author{
Liyan Zhou \\ The North Minzu University \\ Yinchuan, China 750021
}

\begin{abstract}
The study surveys the frequency of first person plural pronouns in single-authored scientific articles using a self-made corpus. The referential meaning and pragmatic function of the pronouns are analysed. The results indicate that first person plural pronouns in most cases are used as inclusive reference. Using first person plurals then may draw the reader closer in terms of communicative effect and reveals the author's awareness and strategy of communication.
\end{abstract}

Keywords-single-authored scientific article; first person plural pronouns; referential meaning; pragmatic effect

\section{INTRODUCTION}

Academic writings, scientific academic papers in particular, have undergone great changes in style in the past decades. Traditionally academic writers were taught to use the third person point of view and the passive voice to ensure an impersonal, objective tone for science writing. The last decade of the 20th century saw a shift mind. Some scientists as well as stylists suggested a more natural and personified first person point of view. Day (1998, 331), for instance, objected expressions like "it was found", which for him is not accurate as it seems and is unnecessary. He advocated that writers of academic papers use "I" or "we" instead of "the author" to start sentences. Webb (1992) argued that "the use of neutral, anonymous third person is deceptive" because it "obliterates the social element of the research process". With more and more academic papers prefer the first person, the third person point of view, on the contrary, was regarded as mundane, stubborn, and an evading of responsibility. To use the first person is to take responsibility (Mhor, 1999; Winslow et al, 2000. Using first person pronouns is taken as means of self-promotion, of seeking recognition from the academic circle (Hyland, 2001; Harwood, 2005) ; authors of different academic and language background show different characteristics concerning the using pf pronouns (Hyland, 2001), New hands(Tang, 1999; Hyland, 2002)and nonnative writers hold a more conservative attitude towards the use of first person pronouns (Molino, 2010) . Researchers also did pragmatic analysis on the self-referred first person pronouns, its inclusive reference (Kuo, 1999 ) and their pragmatic functions (Hyland, 2001; Martnez, 2005) . Many researchers noticed that plural pronouns are used quite commonly, even if it is by a single author. But few research has been done for this, among which Kuo holds that "we" used by a single author is an attempt to weaken a self-centered image. Most researchers mentioned this phenomena but did not probe further. A close up analysis of the seemingly paradoxical phenomena might help to understand the academic culture behind, which is the aim of this paper.

\section{RESEARCH QUESTION AND METHOD}

I intend to survey the use of the first person in single authored scientific articles for its pragmatic effect, trying to answer the following questions: how frequently are the first person pronouns used by a single author? What is the referential meaning? How is the pragmatic effect?

The corpus is composed of altogether 36 single-authored articles taken from Annals of Physics with the publishing date ranging from 1996 to 2014. Choosing this journal is because as the leading journal of physics, Annals of Physics in a way shall set an example of writing styles for thesis writers. The central aim of this paper is to analyze the referential and pragmatic meaning of the used plural pronouns. Comparison between subjects are not a concern of this paper, so no articles from other fields are included. The number of words of all the articles chosen is 315,150 in total, among which 29 articles are authored by native English users, 7 are by nonnative users (merely based on name and the institution). First, the frequency of first person plural pronouns is counted with a view to survey a single author's preference for plural pronouns. The referential and pragmatic meaning of these pronouns are then analyzed to understand why the authors prefer to use first person plurals. The research is done based on both the quantitatively statistics of data and a qualitative analysis of the details.

\section{RESULT AND DISCUSSION}

I converted the 36 articles into txt form(without considering the loss of some special characters in the process of converting) using acrobat and counted the frequency of the first person pronouns using antconc (see "Table I").

From the table, we can see that the first person plural "we" is used so frequently in single authored articles. Among the 36 articles, only one paper does without it. The usage percentage of "we" is $97.22 \%$, with the correspondent objective case and possessive case also frequently used. In contrast, the first person singular "I" is used much less frequently, appearing altogether 71 times. And it should be pointed out that for 11 times it is used with a general reference(similar to "one") and these 11 times shall not be included in the pragmatic analysis. The first person plurals in 
all account for up to $97 \%$ of the first person pronouns in use

in the database.

TABLE I. The UsAge FreQuency OF First PERSON Pronouns

\begin{tabular}{|c|c|c|c|c|c|c|}
\hline \multicolumn{2}{|c|}{ First person pronouns } & Times appearing & $\begin{array}{c}\text { frequency (per10 } \\
\text { words) }\end{array}$ & In how many articles & $\begin{array}{c}\text { percentage } \\
(\%)\end{array}$ & $\begin{array}{c}\text { Percentage in contrast } \\
(\%)\end{array}$ \\
\hline \multirow{3}{*}{$\begin{array}{l}\text { First person } \\
\text { plurals }\end{array}$} & we & 2117 & \multirow[t]{3}{*}{781} & \multirow{3}{*}{$\begin{array}{l}35 \\
27 \\
29\end{array}$} & 97.22 & \multirow[t]{3}{*}{$97.02 \%$} \\
\hline & us & 124 & & & 75.00 & \\
\hline & our & 220 & & & 80.56 & \\
\hline \multirow{3}{*}{$\begin{array}{c}\text { First person } \\
\text { singulars }\end{array}$} & I & 71 & \multirow[t]{3}{*}{24} & \multirow{3}{*}{$\begin{array}{l}13 \\
4 \\
8\end{array}$} & 36.11 & \multirow[t]{3}{*}{$2.98 \%$} \\
\hline & me & 2 & & & 11.11 & \\
\hline & my & 2 & & & 22.22 & \\
\hline \multicolumn{2}{|c|}{ In to } & 2536 & 805 & 36 & 100 & $100 \%$ \\
\hline
\end{tabular}

Since there is only one author for the articles, the use of first person plurals seem awkward. Why are they still so frequently used? A detailed analysis of the pragmatic function of these pronouns is necessary. So I chose 9 from the articles for a detailed survey, trying to include those with singulars and plurals appearing in the same article. The referential meaning and the pragmatic function are analyzed as follows.

\section{A. The Referential Meaning of the First Person Plurals}

Generally speaking, the reference of the word "we" is either inclusive or exclusive. An inclusive reference includes both the speaker/writer and the hearer/reader while an exclusive referent excludes the hearer/reader. Hence the exclusive reference in these papers are further divided into two parts.

1) Referring to the author only (I), for example: In a recent work [1] we have advocated the Chebyshev semispectral method demonstrating its efficiency in solving some typical differential and integral equations emerging in quantum mechanics. (Deloff, A. 2006)

The "recent work" mentioned is actually made by the author himself with no coworkers. So the "we" here refers to "I". For another example:

We remind the reader that a "factorizable" model in the intrinsic physical interpretation...(Schroer, Bert. 1999)

Since this sentence is intended to remind the reader of something, so the "we" used is actually referring to the author.

2) Referring to the author and possible coworkers(I+they): Sometimes the author prefers "we" instead of "I", trying to diminish a self-centered image. By "we" the reader shall assume that there is a related individual or research group behind the author. In such a case, "we" suggests an inclusion of "they"—-some relevant researchers in the circle, though not direct participants, who might support the author's argument.

As the weak interactions do not conserve parity, we know that the gauge fields are coupled in a chirally nonsymmetric way to the fundamental fermions.

We call it the grand confluent hypergeometric function. (Creutz, M. 2014)

Here, for instance, "we" is to activate the reader's possible background knowledge, or to suggest some commonplace knowledge of this field. The referential meaning of the first plural might or might not include the readers, depending on the readers themselves, but it definitely is meant to include "they", the common knowledge sharers.

The inclusive reference of "we" can also be divided into two types.

a) Referring to the bilateral relation between the author and the reader $(I+y o u)$.

Following are some examples.

Finally, we are going to consider the case where both, the Coulomb and the linear potential are present. (Deloff, A. 2006)

These dense subspaces become Hilbert spaces in their own right if we use the graph norm of the Tomita operators. (Schroer, Bert. 1999)

Since all hoppings couple $\mathrm{a}$ and $\mathrm{b}$ sites, the sign of the Hamiltonian is reversed if we replace each $b$ operator by its negative. (Creutz, M. 2014)

We wish to recall that with non-symmetric matrices the accuracy of the standard library procedures is believed to be not as good as in the case of symmetric matrices. (Deloff, A. 2006)

b) Referring to the author, the reader and anybody else (I+you+they)

Of course, we live in a four dimensional world; so, it is perhaps worth mentioning some of the reasons these two dimensional models are worth studying. (Creutz 2006)

What we perceive as the colour 'green' corresponds not always to some discrete or narrow range of values of kc but in general to a weighted average .... (Field, J. H. 2006)

Here "we" is a general reference to all human beings.

Above are cases with various referential meaning of the first person plurals. Then in what context are these pronouns used and what pragmatic function do they have? Let's take some examples for further analysis.

\section{B. The Pragmatic Function of the First Person Plurals}

The pragmatic functions are divided into 7 types according to some shared feature of scientific academic writing. The statistics show the how frequently these functions are realized by first person plurals and singulars respectively. 
TABLE II. The Pragmatic FunCtions of the First PERSON Pronouns

\begin{tabular}{|c|c|c|c|c|c|c|c|c|}
\hline & $\begin{array}{c}\text { To state the } \\
\text { aim (intention, } \\
\text { presupposition } \\
\text { ) }\end{array}$ & $\begin{array}{c}\text { To introduce } \\
\text { background, } \\
\text { method and } \\
\text { design }\end{array}$ & $\begin{array}{c}\text { To explain the } \\
\text { calculating or } \\
\text { experiment } \\
\text { process }\end{array}$ & $\begin{array}{c}\text { To present a } \\
\text { new opinion } \\
\text { or draw a } \\
\text { conclusion }\end{array}$ & $\begin{array}{l}\text { To cite or refer to } \\
\text { the author's } \\
\text { previous research }\end{array}$ & $\begin{array}{l}\text { To clarify the } \\
\text { concepts or for } \\
\text { complements }\end{array}$ & $\begin{array}{c}\text { acknowl } \\
\text { edgemen } \\
\text { ts }\end{array}$ & total \\
\hline $\begin{array}{c}\text { We (us, } \\
\text { our) }\end{array}$ & 18 & 23 & 161 & 15 & 3 & 3 & -- & 224 \\
\hline I(me, my) & 12 & 8 & 27 & 1 & 2 & 2 & 6 & 58 \\
\hline
\end{tabular}

From "Table II", we may find that the first person plurals are used more widely than the singulars for various purposes. All the functions have been realized via the plurals except for acknowledgements. And among these, the highest frequency is for explaining the calculating or experiment process. With no exception, all the authors choose to use singular form for acknowledgements. Obviously, the plurals are used much more frequently than the singulars. The rate is about $6: 1$. Now let's take some examples to examine the actual effect of the pronouns.

In academic writing, the research objective should be given at the beginning. The intention of the researcher might also be explained in the abstract, introduction or reemphasized in the body argument. The corpus data reveal that many researchers prefer to use a first person plural followed by predicate verbs like "consider", "expect", "hope", and "intend" to express the intention.

In this paper we study the black hole solutions of a class of two-dimensional gravity-scalar theories with generic power-law scalar potential. (Mignemi, S. 1996)

The present paper is in the same vein, but here we wish to focus our attention solely on the heavy quarkonium momentum space bound-state problem. (Deloff, A. 2006)

For our problem we want to consider excitations on the half filled system. (Creutz, M. 2014)

A common sense is that a personal intention should be given by "I". But in these single-authored articles, the first person plurals are more commonly used. From the above exemplified sentence, we may find that the author intentionally uses the plural form instead of the singular form to diminish his or her image as a single lecturer, trying to activate the joint participation of the author and the reader. The presumed community of "you and I" is guaranteed by the use of the pronoun "we".

In introduction, the writer usually gives a literature review, introduces the research method and the writing structure. In this part too the plural pronouns appear quite frequently.

This paper is organized as follows: in Section 2 we review the model and discuss the physical properties of its exact black hole solutions. In section 3, we discuss the conformally related theory formulated in terms of the metric which is relevant for string theory. (Mignemi, S. 1996)

By using the three term recurrence formula [5], we obtain analytic power series expansion in closed forms of 192 solutions of Heun function for polynomial and infinite series. (Choun, Y. S. 2013)
Similarly, in these sentences, the referential meaning of "we" is inclusive of the readers, posing an inviting hand to the readers for the coming part.

In the discussion and reasoning, the first person plurals are used very often. These sentences are usually interwoven in data and formulas, serving a transitional and explicating function.

Because of periodicity in $\mathrm{p}$, we can restrict $-\pi<\mathrm{p} \mu \leq$ $\pi$. (Creutz, M. 2014)

Let us now consider the case of nonvanishing $c$. (Mignemi, S. 1996)

To obtain the propagator in the hard thermal loop approximation, we must add the gauge-fixing term to (B.4): (Weldon, H. A. 1999)

If we only consider cyclic (with respect to the vacuum) relatively local fields, then we obtain transitivity of the causality for the resulting fields. (Schroer, Bert. 1999)

We use the $d=3+1$ Wigner $(m, s)$-representations as an illustrative example. (Schroer, Bert. 1999)

Now we do the contour shifting according to (48). We only pick up poles from the coefficient function $\mathrm{am}+\mathrm{k}$. As a result we get the additional factor ..... (Schroer, Bert. 1999)

Traditionally this expository sentences are to be given in an impersonal statement. When they're begun with words like"we" or "our" they lead the readers into an interactive atmosphere. The dry logical reasoning and calculus process becomes more lively and the writing is to be more communicative and effective.

However, in acknowledgements where the author can directly express personal feelings all the authors choose to use the singular form. For example:

I am indebted to Hrach Babujian, Andreas Fring, and Michael Karowski for many discussions. (Schroer, Bert. 1999)

I thank Bogdan Nicolescu. The discussions I had with him on number theory was of great joy. (Choun, Y. S. 2013)

Here the authors prefer to present themselves as individualized persona.

From the above analysis we may find that in most cases the first person plurals are inclusive reference including the readers. That is to say, the major function of the first person plurals are not to conceptually refer to any specific researchers, but serve pragmatically an invitation of involvement of the readers. The significance of these plurals 
is not for reference but for communication, which is actually a writing strategy. This can be very clearly seen in singleauthored papers like these. Take as an example a paper using both"I" and "we"(Schroer, Bert. 1999), we can see very clearly the difference between the two first person pronouns. There are 15146 words in this paper(including the abstract and acknowledgements). The plurals "we", "us", "our" appear respectively 74, 3, 12 times; the singulars "I", "me", "my" appear respectively 12, 1, 6 times. When stating the research aims, personal intentions and acknowledgements, the author chose singulars, for example:

In this paper I continue the study of the new framework of modular localization....

For a mathematical and conceptual background I refer to [33] and to my notes [42], ...

I would not expect that the scattering boundary condition ...can be chosen...

I am not an expert on string theory; therefore I have limited my search to QFT.

Let me finally address the important question of whether the concept of modular localization can be expected to lead to a nonperturbative approach for...

I am indebted to Hrach Babujian, Andreas Fring, and Michael Karowski for many discussions. I owe special thanks to Michael Karowski for the patience with which he explained many subtle points about...

While in the specific reasoning and calculating, the author chose to use plural forms more. For example,

For its existence we have to make an assumption which we presently are not able to derive within the framework of algebraic QFT. We intend to use this object in order to prove [17] the uniqueness of the main inverse problem of QFT:

Here we used a more precise notation which distinguishes between...

..., here we will present them in more details and also use the opportunity to correct some earlier errors and remove possible causes of misunderstandings in my own paper.

Here $\mathrm{K}$ denotes the infinitesimal generator of the L-boost and we used a field theoretic notation $\mathrm{A}^{*}\left(\mathrm{~g}^{\wedge}\right)$ for a wedge localized smeared scalar complex free field of the type (3)

In this article, the author shows a clear stance on the use of plurals: whenever it comes to attitude and intentions he definitely presents his ideas to the readers as an individual; while in the argument, he intentionally uses plurals to make the process more conversational, encouraging the readers to take a more active part. Compared with the impersonal third person point of view, the first person point of view, plural forms in particular, reveals that the science writers are more conscious of a community constructed jointly by the writer and the reader. In some articles, the author even provides directly some reading tips to the readers, pointing out parts that require close reading and parts that can be skimmed:
Now we come to the crucial part of the modular localization method, (Schroer, Bert. 1999)

As this paper is a long one, the reader is recommended to look first at the concluding section for an overview, returning later to any earlier sections that contain material of particular interest. (Field, J. H. 2006)

Some writers even take into consideration different reading levels and offer very specific suggestions:

For those readers who are familiar with Unruh's work, we mention that ....

In the remaining part of this section I make some pedagogical remarks for the non-expert reader on...(Schroer, Bert. 1999)

Day(1998:22) held that the major purpose of scientific writing is to transfer a clear message to the readers, so the various needs of readers should be taken into account. With a more inclusive plural pronoun, the author shows care and respect to the readers. The writing is thus more like a communicative seminar, not a preaching lecture. In daily communication, first person plurals have very rich pragmatic functions. For example, a doctor may ask the patient, "how are we feeling today?" Though actually referring to "you", the plural "we" here expresses empathy and helps relieve pressure. When one wakes up in the morning he or she might murmur "we've got to get up" despite the fact that there' s no others there in bed. The "we" used this way opens an imagined conversation with oneself, creating a pushing effect on oneself. In scientific academic articles, a sphere where objectiveness ad impersonality were emphasized in the past, the use of first person plurals proved a certain shift of attitude towards a more communication-oriented style.

\section{CONCLUSION}

An analysis of the corpus with single-authored scientific articles indicates that most writers tend to use first person plural pronouns rather than singulars. Though some writers use both under various circumstances, most readers still choose to use indiscriminately the plural "we" all along. As to the referential meaning of the plural pronouns in use, there are both exclusive cases and inclusive ones; in most cases they are inclusive. The exclusive referents of "I" plus "they" might help weaken the self-centered profile of the author, and also the hidden message is that there might be coworkers or consultant or help providers for the research, in spite of a single author. So in a single-authored paper, you might more likely to find a more lengthy acknowledgements (Hartley, 2009)

In these articles, the pragmatic function of the first person plurals are certainly more significant than their referential meanings. Among these functions, the inclusive reference of both "I" and "you" serve a persuasive and inviting function for the readers. The plural form in this case is more polite and amiable than the singulars. The readers are thus drawn closer to the writer and the reading process made more pleasant. Some readers take the use of first person pronouns as a sign of the author's intention to construct a self-identity as well as a willingness to cooperate (Hyland, 2001; Wu, 
2013) . But the distinctive phenomena of single authors using first person plurals discussed here indicates that the writers have a strong will to be informative but communicative as well, and the plural pronouns are in a way a writing strategy. As has been shown, the author who prefers to use "I" to talk about personal intention chooses to use "we" in the discussion and calculus process, which serves a more expressive rather than descriptive effect.

In Day's opinion (1998: 333), if the author uses first person pronoun, both plural and singular forms should be used. But in single-authored papers, plural first person pronouns are so commonly used that sometimes they are even over used, which seems to be a new extreme. A communicative reading atmosphere, anyway, is what the authors tend to create through conversations initiated by all the "we" and "us".

\section{REFERENCES}

[1] Biber, Douglas \& Susan Conrad. (2009). Register, Genre and Style. Cambridge: CUP.

[2] Day, Robert A.(1998) How to Write and Publish a Scientific Paper. Arizona: Oryx Press.

[3] Harwood, N. (2005). "Nowhere has anyone attempted...In this article I aim to do just that" A corpus based study of self-promotional $I$ and we in academic writing across four disciplines. Journal of Pragmatics, 37: 1207-31.

[4] Hartley, James.(2009) Single Authors Are Not Alone: Colleagues Often Help. Journal of Scholarly Publishing. Jan: 108-13.

[5] Hyland Ken. (1997) Scientific Claims and Community Values: Articulating an Academic Culture. Language and Communication, 17(1): 19-31,.

[6] Hyland, Ken. (2001) Humble Servant of the discipline? Self-mention in research articles. English for Specific Purposes 20.

[7] Hyland, K. Authority and invisibility: Authorial identity in academic writing. Journal of Pragmatics,2002,34(8): 1091-1112.

[8] Hyland, Ken. (2005) Metadiscourse: Exploring Interaction in Writing. London: Continuum.

[9] Kou, C. H. (1999) The Use of Personal Pronouns: Role Relationships in Scientific Journal Articles. English for Specific Purposes, 2: 121138

[10] Martnez, I. A. (2005) Native and Non-native Writers Use of First Person Pronouns in the Different Section of Biology Research Articles in English. Journal of Second Language Writing, 14(3): 174190.

[11] Mohr W.(1999) Reflections on Writing. Nursing Outlook, 47:198-9.

[12] Molino, Alessandra. (2010). Personal and Impersonal Authorial References: A Contrastive Study of English and Italian Linguistics Research Articles. Journal of English for Academic Purposes, 9: 86101.

[13] Tang R, John S.(1999) The"I"in Identity: Exploring Writer Identity in Student Academic Writing through the First Person Pronoun . English for Specific Purposes, 18:23-39

[14] Webb, Christine(1992). The Use of the First Person in Academic Writing: Objectivity, Language and Gatekeeping. Journal of Advanced Nursing. 17:747-52.

[15] Winslow, Elizabeth H.\& Cathie E Guzzetta.(2000) We Need to Use First Person Pronouns in Our Writing. Nursing Outlook, 48:156-7. 